\title{
FORMULATION AND EVALUATION OF METFORMIN HYDROCHLORIDE SUSTAINED-RELEASE ORAL MATRIX TABLETS
}

\section{PADMAJA BOOKYA ${ }^{1 *}$, RAMAKRISHNA RAPARLA ${ }^{1}$, HARIKISHAN PRASAD SRIRAMULA ${ }^{1}$, SUNITHA TARRIGOPULA ${ }^{2}$, SRIDHAR VANGA ${ }^{2}$}

${ }^{1}$ Department of Pharmaceutics, Vaageswari Institute of Pharmaceutical Science, Karimnagar - 505 481, Telangana, India. ${ }^{2}$ Department of Pharmaceutical Chemistry, Vaageswari Institute of Pharmaceutical Science, Karimnagar - 505481 , Telangana, India. Email: bookyapadmaja@gmail.com

Received: 08 July 2017, Revised and Accepted: 11 December 2017

\section{ABSTRACT}

Objective: The aim of this investigation was to develop and optimize metformin hydrochloride matrix tablets for sustained release application. The sustained release matrix tablet of metformin hydrochloride was prepared by wet granulation technique using chitosan, xanthan gum, and hydroxypropyl methylcellulose at varying concentrations.

Material and Methods: Extended release of metformin hydrochloride matrix tablets was prepared by wet granulation method. The influence of varying the polymer ratios was evaluated. The excipients used in this study did not alter physicochemical properties of the drug.

Results: All the batches were evaluated for thickness, weight variation, hardness, and drug content uniformity. The in vitro drug dissolution study was carried out using USP apparatus Type II, paddle method, and the release mechanisms were explored. Mean dissolution time is used to characterize drug release rate from a dosage form and indicates the drug release is retarding efficiency of the polymer. This study revealed that as the concentration of matrix material increased, drug release from matrices decreased. This may be due to slower penetration of the dissolution medium into the matrices.

Conclusion: Formulation with chitosan MS1 drug release was 86\%, xanthan gum MS489\%, and finally MS7 with hydroxypropyl methyl cellulose which exhibited the highest drug release retardation also had the lowest matrix concentration. Hence, lower concentration of polymers is suitable to prepare metformin hydrochloride tablets compared to higher concentrations.

Keywords: Sustained release tablet, Metformin hydrochloride, Hydroxypropyl methyl cellulose, Xanthan gum, Chitosan.

(C) 2018 The Authors. Published by Innovare Academic Sciences Pvt Ltd. This is an open access article under the CC BY license (http://creativecommons. org/licenses/by/4. 0/) DOI: http://dx.doi.org/10.22159/ajpcr.2018.v11i3.21211

\section{INTRODUCTION}

Oral route of administration is considered as widely accepted route due to ease inconvenience by self-administration, compactness, and simple manufacturing process. It was observed that drugs administered by oral route produce $90 \%$ of systemic effects [1]. Tablets being most popular oral formulations available in the market are widely preferred by patients and physicians alike in long-term therapy for the treatment of chronic conditions [2]. Conventional dosage form produces the wide range of fluctuation in drug concentration in bloodstream which leads to a loss in drug effectiveness or increases the incidence of side effects with subsequent undesirable toxicity and poor efficiency. However, sustained or controlled drug delivery systems can decrease the frequency of the dosing and also increases effectiveness of the drug by localization at the site of action, reducing the dose required and providing uniform drug delivery [3]. Sustained release preparations are helpful to reduce the dosage frequency and side effects of drugs and improve patient's convenience. Sustained release matrix tablet is relatively easy to fabricate by incorporating the drug in slowly dissolving or inert porous polymer materials [4]. Drug release through matrix system is determined by water penetration, polymer swelling, drug dissolution, drug diffusion, and matrix erosion that lead to a rapid formation of external layer, allowing drug release modification [5]. The major therapeutic goals in subjects with Type II diabetes are to optimize blood glucose control, reduce overweight, and elevated blood pressure. However, pharmacological treatment with oral hypoglycemic agents or insulin is required [6]. An oral biguanide metformin hydrochloride used in the management of Type II diabetes, a common disease that combines defects of both insulin secretion and insulin action. Unlike other antidiabetic drugs metformin Hcl does not induce hypoglycemic at any reasonable dose, and hence it is called as an antihyperglycemic rather than a hypoglycemic drug. The compound has a relatively short plasma half-life of 1.5-4.5 $\mathrm{h}$ with low bioavailability of $50-60 \%$ so need for the administration of 2-3 times a day when larger doses are required can decrease patient compliance [7]. The objective of the present study was to prepare oral sustained release matrix tablet of metformin hydrochloride by wet granulation using polymers such as chitosan, xanthan gum, and hydroxypropyl methylcellulose and to evaluate the effect of concentration of polymers for the release of the drug. Such a sustained release formulation if achieved would be substantially more affordable to the patient.

\section{MATERIAL AND METHODS}

Materials

Metformin hydrochloride was the gift sample from Aurobindo Pharma Ltd., Hyderabad. All other ingredients used throughout the study were of an analytical grade such as chitoson, hydroxypropyl methylcellulose, and xanthan gum were received from Loba Chemicals, Mumbai. Isopropyl alcohol, talc, and magnesium stearate were procured from S.D. Fine Chemicals, Mumbai.

Nine different tablet formulations were prepared using wet granulation method. The composition of tablets was given in Table 1. Sustained-release matrix tablets of metformin hydrochloride were prepared using different polymer ratios. All ingredients were passed through a \#80 sieve weighed on a digital balance (Shimadzu, Japan) and blended. Tablets weighing $750 \mathrm{mg}$ were prepared containing $500 \mathrm{mg}$ of metformin hydrochloride, hydroxypropyl methylcellulose, xanthan gum, and chitosan. Required quantities of drug, diluents, and polymers were mixed thoroughly by 
adding a sufficient quantity of binding agent like isopropyl alcohol slowly. After enough cohesiveness was obtained, the wet mass was sieved through \#16 mesh. The sifted granules were dried at $50^{\circ} \mathrm{C}$ for $1 \mathrm{~h}$ in hot air oven (BTI, Bio Technics, Mumbai). The dried granules were mixed with talc as a diluent and magnesium stearate as a lubricant for $5 \mathrm{~min}$ [8]. Finally, tablets were compressed by $10 \mathrm{~mm}$ punches on 16 Station Rotary tablet machine (Saimach Ltd., India). All tablets were stored in airtight containers for further study. Before compression, the granules were evaluated for their flow and compressibility characteristics.

\section{EVALUATION OF POWDER BLENDS OF METFORMIN HYDROCHLORIDE}

The powder blends of metformin hydrochloride formulations were evaluated before compression to assess the flow properties of the powder.

\section{Bulk density}

Required amount of powder $\mathrm{m}$ was transferred into the measuring cylinder, and apparent volume $\mathrm{V}_{0}$ was measured, bulk density in g per $\mathrm{ml}$ is calculated by the formula.

Bulk density $=\mathrm{m} / \mathrm{V}_{0}$.

Where m-mass of powder, $\mathrm{V}_{0}$ apparent volume.

\section{Tapped density}

After determination of bulk density the measuring cylinder Va volume in $\mathrm{ml}$ was measured initially, later the same cylinder was set for 100 tappings on tapped density apparatus and measure the tapped volume finally $\mathrm{Vb}$. Calculate tapped density in g per $\mathrm{ml}$ by the formula [9].

Tapped density $=\mathrm{Va} / \mathrm{Vb}$.

Where Va - initial volume, $\mathrm{Vb}$ - final tapped volume

\section{Carr's index}

It is an indirect method of measuring powder flow from bulk densities to measure bridge strength and stability. Carr's index of each formulation was calculated according to the equation.

Carr's index $=($ Tapped density - bulk density $) /$ tapped density $* 100$.

\section{HAUSNER RATIO}

It is essential to determine the compressibility strength of powder. It was calculated according to equation [10].

Hausner ratio $=$ Tapped density $/$ bulk density

Lower Hausner's ratio $(<1.25)$ indicates better flow properties than higher ones $(>1.25)$

\section{Angle of repose}

Accurately weighed quantity of powder was transferred into a funnel which was adjusted to a height of $2 \mathrm{~cm}$ in such a way that the tip of funnel touches apex of a pile of powder heap [11]. Finally, the height and radius of powder cone were measured using the following equation.

$\tan \theta=\mathrm{h} / \mathrm{r}$.

Where $\theta=$ angle of repose, $h=$ height of pile, $r=$ radius of pile base.

\section{EVALUATION OF METFORMIN HYDROCHLORIDE SUSTAINED} RELEASE MATRIX TABLETS

\section{Weight variation}

Ten tablets from each batch were selected randomly and weighed on a digital balance (Shimadzu, Japan) individual weights were compared with average weight. The percentage difference in the weight variation should be within the permissible limits [12].

\section{Thickness}

The thickness of all formulations was determined on screw gauge (Pharma Labs, Ahmedabad, India). Standard deviation values indicate all formulations were within the range [13].

\section{Tablet hardness}

Hardness of the tablets for shipping or breakage under conditions of storage, transportation, handling depends on hardness which was determined using Monsanto hardness tester [14] (E 30, Dwaraka Mai, Hyderabad)

\section{Friability}

The Friability of five tablets was determined using Roche friabilator (Electrolab, Mumbai). This device subjects tablets to the combined effect of abrasions and shock in a plastic chamber revolving at $25 \mathrm{rpm}$ and dropping the tablets at the height of 6 inches in each revolution. Pre-weighed sample of tablets was placed in the friabilator and was subjected to 100 revolutions dedusted and reweighed [15]. The friability $(F)$ is given by the formula:

$\mathrm{F}=\left(1-\mathrm{W}_{0} / \mathrm{W}\right) * 100$

Where, $\mathrm{W}_{0}$ is the weight of the tablets before the test. $\mathrm{W}$ is the weight of the tablet after the test.

\section{Drug content}

Five tablets were weighed accurately and powdered, powder equivalent to $10 \mathrm{mg}$ of drug was dissolved in phosphate buffer $\mathrm{pH} 7.4$, filtered using $0.2 \mathrm{um}$ membrane filter [16]. The drug content was measured by ultraviolet (UV)-spectrophotometer (Shimadzu, Japan) at $233 \mathrm{~nm}$.

\section{In vitro drug release}

In vitro, drug release studies for the prepared tablets were conducted using USP Type II paddle dissolution apparatus (Electrolab, Mumbai, India) at $100 \mathrm{rpm}$. One matrix tablet was placed in each flask of dissolution apparatus the study was conducted in $900 \mathrm{ml} 0.1 \mathrm{~N} \mathrm{Hcl}$ $37 \pm 0.5^{\circ} \mathrm{C}$ in first $2 \mathrm{~h}$ and later $900 \mathrm{ml}$ of phosphate buffer $\mathrm{pH} 7.4$ for remaining 12 h. $5 \mathrm{ml}$ samples were withdrawn at regular intervals and same volume was replaced to maintain sink conditions [17]. The samples were analyzed after suitable dilutions with UV-spectrophotometer (Shimadzu, Japan) at $233 \mathrm{~nm}$. All the experimental units were carried in triplicates.

\section{Kinetic analysis of dissolution data}

The in vitro drug release data were fitted into zero-order, first-order, and Higuchi by employing the method of least squares the mechanism of drug release was compared for all the formulations.

$\mathrm{Mt} / \mathrm{M} \infty=\mathrm{Ktn}$

$\mathrm{Mt} / \mathrm{M} \infty=\mathrm{b}+\mathrm{k} 2 \mathrm{t} 1 / 2$

$\mathrm{Mt} / \mathrm{M} \infty=\mathrm{a}+\mathrm{k} 3 \mathrm{t}$

In Peppas equation, $\mathrm{Mt} / \mathrm{M} \infty$ is the fraction of drug released up to time $\mathrm{t}$, $\mathrm{K}$ kinetic constant and $\mathrm{n}$ is the release exponent indicative of the release mechanism. In Higuchi and zero-order release equations, k1, k2, and k3 are constants [18]. On the other hand, Higuchi equation expresses a diffuse release mechanism.

\section{RESULTS AND DISCUSSION}

In the present work, sustained-release tablets of metformin hydrochloride were prepared by wet granulation method as it was feasible and simple. Formulations were prepared by varying amount of polymers to see the effect of various polymer concentration on drug release rate. The prepared mixed powder was physically evaluated with some parameters and was suggested to be suitable for compression into tablets. 
Evaluation of powder blends of metformin hydrochloride sustained-release tablets

The method employed for the preparation of metformin hydrochloride sustained-release tablets was wet granulation method, mixture of drug and excipients should possess good flow properties. The flow properties of powder blend metformin hydrochloride were checked by studying the angle of repose, compressibility index, and Hausner's ratio. The powder blends were found to be free flowing with good flow properties as shown in Table 2.

Bulk density was found to be in the range of $0.500-0.640(\mathrm{~g} / \mathrm{ml})$ and tapped density between 0.623 and $0.647(\mathrm{~g} / \mathrm{ml})$ for all the formulations. The $\%$ compressibility index was calculated using the density data. The obtained values $11.15-15.91 \%$ which were found to be good flow and Hausner's ratio values were in the range of 1.131-1.189 for all powder blends. This was further supported by the angle of repose values between 17.17 and $20.55^{\circ}$. As it was below $30^{\circ}$ it indicated good flow properties of powder blend.

Preparation and evaluation of metformin hydrochloride sustainedrelease tablets

The studies were carried to find the effect of different concentrations ranges of polymers. Evaluation data of metformin hydrochloride sustained-release tablets were shown in Table 3.

All the tablets were having beveled edged flat surface in round shape with white color. Average weight of tablets was in the range of $740-769 \mathrm{mg}$ and weight variation was according to the limits. Thickness of the tablets was in the range of 4.18-5.32 $\mathrm{mm}$. The hardness of tablets was determined and found in the range of $6.10-7.41 \mathrm{Kg} / \mathrm{cm}^{2}$. As the aim of the study is to release the drug slowly, hardness was kept in the high range. The $\%$ of content uniformity in tablets was determined by UV spectrophotometer (Shimadzu, Japan). All formulations are subjected to content uniformity and were in the range of $98.4-101 \%$. It was observed that all the formulations were as per I.P. specification limits (90.0-110.0\%). The \% drug release data and plot which were obtained for the metformin hydrochloride sustained-release tablets in $0.1 \mathrm{~N} \mathrm{Hcl}$ in first $2 \mathrm{~h}$ and phosphate buffer $\mathrm{pH} 7.4 \mathrm{up}$ to $12 \mathrm{~h}$ at $233 \mathrm{~nm}$ was shown in Table 4 and Fig. 1, respectively.

From the drug release it was observed that at low concentrations of the polymers, the matrices of the tablets readily disintegrated during dissolution test. This was not, however, the case when the content of the matrix former was increased, thus indicating that a minimum level of the polymers is required to form a proper matrix that would not readily disintegrate. This study revealed that as the concentration of matrix material increased, drug release from matrices decreased. This may be due to slower penetration of the dissolution medium into the matrices. Formulations with chitosan drug release were $86 \%$ for MS1, xanthan gum was $89 \%$ for MS4, and finally MS7with hydroxypropyl methyl cellulose for $92 \%$ which exhibited highest drug release retardation with the lowest matrix concentration. Hence, a lower concentration of polymers is suitable to prepare metformin hydrochloride tablets compared to higher concentrations. The initial drug release may be attributed to "burst" release of the drug on the tablet surface. It has stated that the drug particles present on the surface of a matrix system

Table 1: Formula of metformin hydrochloride sustained-release tablets

\begin{tabular}{|c|c|c|c|c|c|c|c|c|c|}
\hline Ingredients & MS1 & MS2 & MS3 & MS4 & MS5 & MS6 & MS7 & MS8 & MS9 \\
\hline Metformin hydrochloride & 500 & 500 & 500 & 500 & 500 & 500 & 500 & 500 & 500 \\
\hline Chitosan & 100 & 150 & 200 & - & - & - & - & - & - \\
\hline Xanthan gum & - & & - & 100 & 150 & 200 & - & - & - \\
\hline HPMC & - & - & - & - & - & - & 100 & 150 & 200 \\
\hline Magnesium stearate & 10 & 10 & 10 & 10 & 10 & 10 & 10 & 10 & 10 \\
\hline Talc & 140 & 90 & 40 & 140 & 90 & 40 & 140 & 90 & 40 \\
\hline Isopropyl alcohol & Q.S & Q.S & Q.S & Q.S & Q.S & Q.S & Q.S & Q.S & Q.S \\
\hline
\end{tabular}

HPMC: Hydroxypropyl methylcellulose

Table 2: Evaluation of powder blend of sustained-release tablets

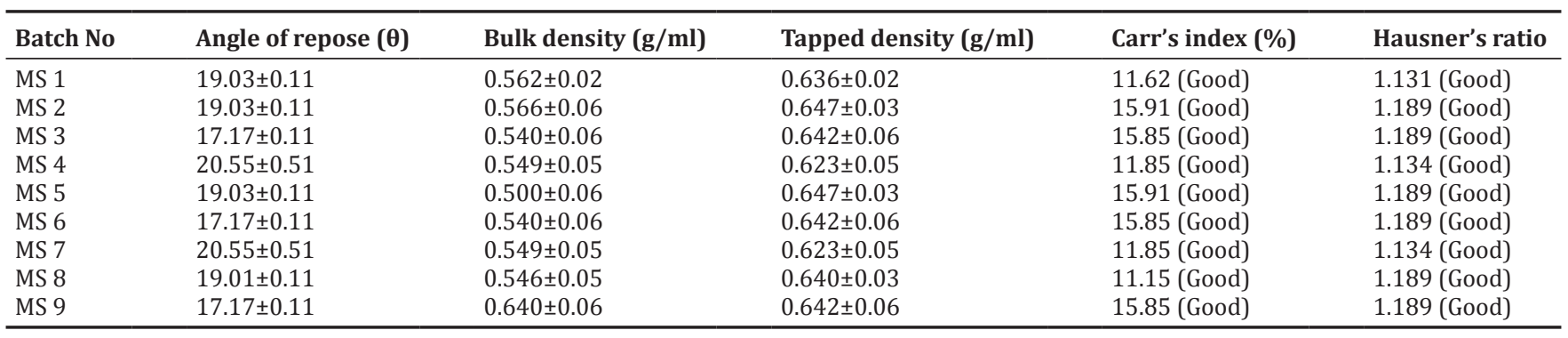

Table 3: Evaluation data of metformin hydrochloride sustained-release tablets

\begin{tabular}{|c|c|c|c|c|c|}
\hline Batch No & Weight variation (mg) a & Thickness $(\mathrm{mm})^{\mathrm{b}}$ & Hardness $\left(\mathrm{Kg} / \mathrm{cm}^{2}\right)^{b}$ & Friability $(\%)^{c}$ & Content uniformity (\%) ${ }^{c}$ \\
\hline MS 1 & $757 \pm 0.86$ & $4.40 \pm 0.01$ & $6.10 \pm 0.23$ & $0.192 \pm 0.57$ & $98.4 \pm 0.73$ \\
\hline MS 2 & $741 \pm 1.16$ & $4.59 \pm 0.05$ & $6.85 \pm 0.25$ & $0.198 \pm 0.12$ & $101 \pm 1.61$ \\
\hline MS 3 & $762 \pm 3.57$ & $4.38 \pm 0.88$ & $7.41 \pm 0.05$ & $0.218 \pm 0.17$ & $99.2 \pm 0.12$ \\
\hline MS 4 & $759 \pm 0.88$ & $4.38 \pm 0.07$ & $7.22 \pm 0.15$ & $0.236 \pm 0.27$ & $99.1 \pm 0.40$ \\
\hline MS 5 & $758 \pm 0.88$ & $4.18 \pm 0.07$ & $6.15 \pm 0.98$ & $0.216 \pm 0.07$ & $99.8 \pm 0.19$ \\
\hline MS 6 & $769 \pm 0.12$ & $5.32 \pm 0.07$ & $6.15 \pm 0.83$ & $0.226 \pm 0.21$ & $99.1 \pm 0.14$ \\
\hline MS 7 & $740 \pm 0.88$ & $4.18 \pm 0.03$ & $6.15 \pm 0.75$ & $0.246 \pm 0.78$ & $99.8 \pm 0.78$ \\
\hline MS 9 & $745 \pm 0.12$ & $4.36 \pm 0.15$ & $6.15 \pm 0.56$ & $0.286 \pm 0.32$ & $99.8 \pm 0.42$ \\
\hline
\end{tabular}

Each value is an average of ten determinations ${ }^{\mathrm{a}}$, each value is an average of three determinations $\mathrm{s}^{\mathrm{b}}$, each value is an average of five determination $\mathrm{s}^{\mathrm{c}}$ 
Table 4: \% drug release data of metformin hydrochloride sustained-release tablets

\begin{tabular}{llllllllll}
\hline Time (H) & MS1 & MS2 & MS3 & MS4 & MS5 & MS6 & MS7 & MS8 & MS9 \\
\hline 0 & 0 & 0 & 0 & 0 & 0 & 0 & 0 & 0 & 0 \\
1 & 14 & 17 & 19 & 13 & 16 & 14 & 12 & 15 & 11 \\
2 & 20 & 21 & 27 & 22 & 19 & 26 & 22 & 25 & 16 \\
3 & 26 & 27 & 30 & 31 & 24 & 32 & 33 & 30 & 22 \\
4 & 34 & 33 & 37 & 38 & 29 & 41 & 39 & 36 & 27 \\
5 & 41 & 38 & 45 & 44 & 35 & 48 & 49 & 42 & 32 \\
6 & 47 & 43 & 55 & 50 & 42 & 52 & 53 & 59 & 39 \\
7 & 55 & 53 & 62 & 54 & 57 & 59 & 59 & 63 & 48 \\
8 & 67 & 61 & 67 & 62 & 69 & 61 & 63 & 69 & 58 \\
9 & 73 & 67 & 71 & 68 & 72 & 65 & 70 & 71 & 61 \\
10 & 81 & 71 & 75 & 78 & 79 & 71 & 78 & 75 & 79 \\
11 & 83 & 80 & 82 & 82 & 76 & 79 & 86 & 82 & 83 \\
12 & 86 & 82 & 85 & 89 & 83 & 85 & 92 & 89 & 87 \\
\hline
\end{tabular}

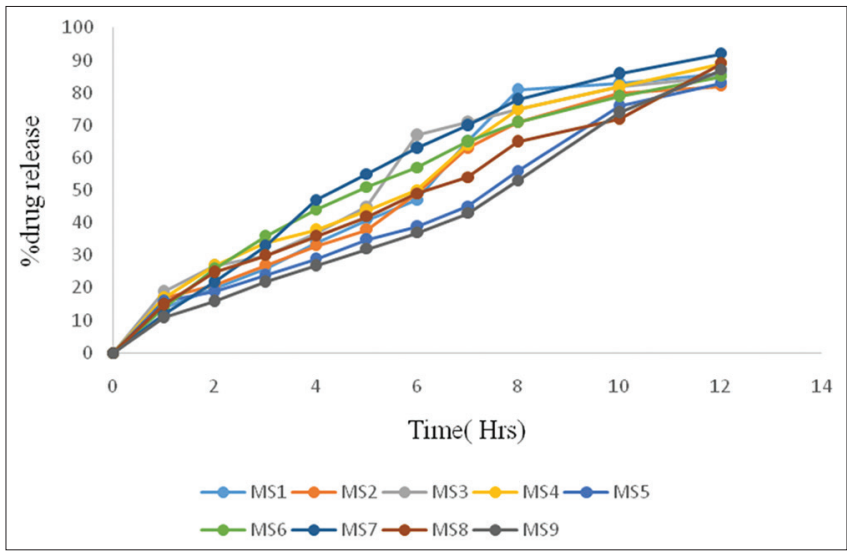

Fig.1: Cumulative \% drug release plot of sustained-release tablets

were initially released into the surrounding media generating many pores and cracks which facilitate further release of drug and also the formation of channels within the matrix.

To describe the kinetics of drug release from matrix tablets, release data were analyzed according to different kinetic equations. The data were analyzed by the regression coefficient method and regression coefficient values $\left(\mathrm{r}^{2}\right)$ of all batches. On analyzing regression coefficient values of all batches, it was found that tablets exhibited almost zero-order kinetics, followed Higuchi model. The in vitro release profiles of the drug from all these formulations could be best expressed by Higuchi's equation as the plots showed the highest linearity $\left(\mathrm{r}^{2}=0.98-0.99\right)$. To confirm diffusion mechanism, the data were fitted into Korsmeyer-Peppas equation.

\section{CONCLUSIONS}

The present investigation was carried out to develop the sustained delivery of metformin hydrochloride for an effective and safe therapy using three polymers such as chitosan, hydroxypropyl methylcellulose, and xanthan gum

The term modified-release dosage form is used to describe products that alter the timing and rate of release of drug substance. A modified-release dosage form is defined"as one for which the drug release characteristics of time course and/or location are chosen to accomplish therapeutic or convenience objectives not offered by conventional dosage forms such as solutions, ointments, or promptly dissolving dosages forms."

It is an oral antidiabetic drug in the biguanide class. It is the first-line drug of choice for the treatment of Type II diabetes in particular, in overweight and obese people and those with normal kidney function.
Formulations with chitosan MS1 drug release are 86\%, xanthan gum MS4 was $89 \%$, and finally MS 7 with hydroxypropyl methylcellulose was $92 \%$ which exhibited the highest drug release retardation, also had the lowest matrix concentration. Hence, a lower concentration of polymer such as hydroxypropyl methylcellulose is optimized batch suitable to prepare metformin hydrochloride tablets compared to higher concentrations. On analyzing regression coefficient values of all batches, it was found that tablets exhibited almost zero-order kinetics, followed Higuchi model.

\section{ACKNOWLEDGMENT}

The authors express their sincere thanks to management Dr. G. Srinivas Reddy, Karim Nagar, India, for providing required facilities to carry out this research work.

\section{REFERENCES}

1. Hadi MA, Babu VL, Narottam P. Formulation and evaluation of sustained release matrix tablets of glimepiride based on combination of hydrophilic and hydrophobic polymers. J Appl Pharm Sci 2012;2:101-7.

2. Patil J, Sarode SM, Sathe B, Jain PV. Formulation and evaluation of sustained release tablets of ritonavir. World J Pharm Pharm Sci 2014;3:857-69.

3. Sanjit KR, Sweet N, Subhasis K, Ketousetuo K. Formulation and evaluation of sustained release bilayer tablets of propranolol hydrochloride. Int J Pharm Pharm Sci 2015;7;264-9.

4. Shanmugam S, Chakrahari R, Sundaramoorthy K, Vetrichelvan T. Formulation and evaluation of sustained release matrix tablets of losartan potassium. Int J Pharm Tech Res 2011;3:526-34.

5. Bisht T, Rishiwer P, Kumar P. Review on matrix tablet. Indo Glob Pharm Sci 2016;6:38-42.

6. Basavaraj K, Mhase SR, Manvi FV. Formulation of extendedrelease metformin hydrochloride matrix tablets. Trop J Pharm Res 2011;10:375-83.

7. Dharmendra S, Kumar JS, Mahapatra S. Formulation and evaluation of sustained release metformin hydrochloride matrix tablet using natural polysaccharide. Am J Pharm Tech Res 2014;4:492-503.

8. Wadher KJ, Kakde RB, Umekar MJ. Study on sustained-release metformin hydrochloride from matrix tablet: Influence of hydrophilic polymers and in vitro evaluation. Int $\mathrm{J}$ of Pharm Inv 2011;1:157-63.

9. Krishnarajan D, Reddy CM, Sasikanth K, Kumar NS, Purushothaman M. Formulation and evaluation of sustained release matrix tablets of levofloxacin using natural polymer pharmacophore. Int Res J 2013;4:146-57.

10. Nagendrakumar D, Ganesh G, Ambarish GS. Sustained release matrix tablets of furosemide. J Pharm Sci 2015;5:105-14.

11. Ch C, Kumar YG, Vishnu YV, Madhuri MM. Metoprolol succinate sustained release matrix tablets-Formulation development and in vitro evaluation. Int J Pharm Pharm Sci 2014;6:481-6.

12. Jyothshna K, Pavan B, Venkateswara B, Pichika M. Formulation and development of multilayer and monolithic extended release matrix tablets of alfuzosin Hcl". Asian J Pharm Clin Res 2013;7:76-9.

13. Patel J, Shah N. Formulation and evaluation of sustained release tablets containing atomoxetine hydrochloride. J Pharm Sci and Biosci Res 2014;4:196-200.

14. Usman M, Ali I, Bibi H, Iqbal J. Preparation and evaluation of controlled release tablets containing mefenamic acid. Clin Exp Pharmacol 2012;2:1-3.

15. Shanmugam S, Babu R, Satheeshkumar S, Shanmugasundaram P. Formulation and evaluation of sustained release matrix tablets of levosulpiride using natural polymer. Asian J Pharm Clin Res 2017; 10:285-92

16. Kanti SM, Giriraj T, Suresh B. Development of sustained release bilayered tablets of diclofenac sodium using natural hydrogel as matrix material drug content. JchrDD 2013;4:53-64.

17. Ajinkya, U., Sanjay, K., Mangesh, B. Design and optimization of sustained release matrix tablet of opipramol hel by using quality by design approach. Asian J Pharm Clin Res 2014;7:227-34.

18. Varma JN, Ch PK, Reddy AK, Raju PP. Evaluation of Moringa oleifera gum as a sustained release polymer in diclofenac sodium tablet formulation. Int J Res Pharm Chem 2014;4:687-93. 